\title{
The role of sleep and sleep disorders in the development, diagnosis, and management of neurocognitive disorders
}

\author{
Michelle A. Miller* \\ Warwick Medical School, University of Warwick, Coventry, UK
}

It is becoming increasingly apparent that sleep plays an important role in the maintenance, disease prevention, repair, and restoration of both mind and body. The sleep and wake cycles are controlled by the pacemaker activity of the superchiasmic nucleus in the hypothalamus but can be disrupted by diseases of the nervous system causing disordered sleep. A lack of sleep has been associated with an increase in all-cause mortality. Likewise, sleep disturbances and sleep disorders may disrupt neuronal pathways and have an impact on neurological diseases. Sleep deprivation studies in normal subjects demonstrate that a lack of sleep can cause attention and working memory impairment.

OPEN ACCESS

Edited by:

Annette Sterr,

University of Surrey, UK

Reviewed by:

David M. Schnyer,

University of Texas, USA

Timo Partonen,

National Institute for Health and

Welfare, Finland

${ }^{*}$ Correspondence:

Michelle A. Miller

michelle.miller@warwick.ac.uk

Specialty section: This article was submitted to Sleep and Chronobiology, a section of the journal Frontiers in Neurology

Received: 23 July 2015 Accepted: 12 October 2015 Published: 23 October 2015

Citation:

Miller MA (2015) The role of sleep and sleep disorders in the

development, diagnosis, and management of neurocognitive

disorders.

Front. Neurol. 6:224.

doi: 10.3389/fneur.2015.00224
Moreover, untreated sleep disturbances and sleep disorders such as obstructive sleep apnoe (OSA) can also lead to cognitive impairment. Poor sleep and sleep disorders may present a significant risk factor for the development of dementia. In this review, the underlying mechanisms and the role of sleep and sleep disorders in the development of neurocognitive disorders [dementia and mild cognitive impairment $(\mathrm{MCl})$ ] and how the presence of sleep disorders could direct the process of diagnosis and management of neurocognitive disorders will be discussed.

Keywords: sleep, sleep disorders, cognition, dementia, neurocognitive disorders

\section{BACKGROUND}

The worldwide prevalence of neurocognitive disorders [dementia and mild cognitive impairment (MCI)] is increasing. Dementia occurs when the brain is damaged and is characterized by memory loss, alongside thinking, problem-solving, or language difficulties.

Alzheimer's disease $(\mathrm{AD})$ is a neurodegenerative disorder in which there is a progressive decline in cognitive function. It is the most common cause of dementia. In 2010, the worldwide prevalence of $\mathrm{AD}$ was estimated to be 35.6 million (1). While the worldwide prevalence for those aged 60 or above is estimated between 5 and 7\%, a higher prevalence in Latin America (8.5\%) and a distinctively lower prevalence in the four sub-Saharan African regions (2-4\%) are reported. The number of cases is rising and is expected to double every 20 years, reaching approximately 115.4 million by 2050 . The economic consequence of this disease is immense. In 2010, it was estimated that the annual cost of dementia was $\$ 604$ billion dollars (2).

Our studies have shown that sleep duration is associated with an increase in all-cause mortality (3). In this review, the relationship between sleep and cognitive function and the role sleep and sleep disorders may have in the prevention, development, and treatment of neurocognitive disorders 
will be considered. Underlying mechanisms are briefly examined along with the public health importance.

\section{Sleep Architecture}

Sleep is not a quiescent state. Two processes govern sleep: the first, the homeostatic process, is often referred to as the "sleep drive," and increases the longer the individual has been awake. The second, the circadian system, refers to the 24-h sleep-wake cycle and governs many physiological processes including production of hormones (e.g., melatonin), gene expression, and body temperature. Sleep and wake cycles are controlled by the pacemaker activity of the superchiasmic nucleus in the hypothalamus region of the brain but can be disrupted by diseases of the nervous system causing disordered sleep.

The high level of brain activity can be detected on an electroencephalogram (EEG). Sleep "architecture" consists of four different stages, and the first three stages (N1, N2, and N3) are made up of progressively deeper, non-rapid eye movement sleep (NREM). Sleep spindles along with K-complexes are defining characteristics of, and indicate the onset of, stage 2 sleep. Slow wave sleep (SWS), which may be referred to as deep sleep, occurs in Stage 3 NREM and is characterized by synchronized EEG activity. The fourth stage is characterized by rapid eye movements (REM) sleep, which can detected by a decrease in muscle activity. In general, an adult will cycle through the four stages approximately every $90-100 \mathrm{~min}$ during the night but the time spent in each stage changes as the night progresses.

\section{Sleep and Aging}

Age-related changes in sleep have been well documented (4). There are changes in sleep architecture, circadian and homeostatic processes as well as changes in the susceptibility to sleep disorders. As we age, total sleep quantity and quality and sleep efficiency decline along with the amount of time spent in deep sleep. As a consequence older people often find it takes them longer to fall asleep, that they have more fragmented sleep and wake up more often and earlier (4-6). Older adults also tend to awaken less from REM sleep and more from NREM sleep than young adults and have a reduced number of sleep spindles and K-complexes in NREM [see review in Ref. (5)].

Studies indicate that aging is associated with reduced NREM and SWS (7), alongside structural brain atrophy, particularly in the frontal lobe regions (8). In a recent study, it was shown that the degree of age-related atrophy of the medial prefrontal gray matter region of the brain is significantly associated with the degree of diminution of SWS activity (9).

In a large cohort study, aging has also been shown to be associated with morning preference and a decrease in sleep efficiency. Sleep evaluations, using polysomnography, were conducted in over 2,000 subjects from the cohort who did not have sleep disorders. Detailed analysis indicated that there might be some gender differences in age-related changes in sleep: While SWS did decrease with age, the effect appeared to be more prominent in men. The study also demonstrated that in NREM, there was a decrease in the spectral power densities within slow waves and fast spindles but that for theta-alpha and beta waves, the spectral power increased with aging. In REM, aging was associated with a progressive decrease in delta waves and an increase in higher frequency waves (10).

\section{Sleep and Cognition (Amnestic and Non-Amnestic Function)}

The term "cognition" refers to a range of mental processes, which can be grouped into two broader categories of amnestic cognitive function (ACF, referring to memory) and non-amnestic cognitive function (nACF, or non-memory). This dichotomy is important in relation to the progression from normal cognitive aging to MCI, since MCI is typically diagnosed as amnestic (aMCI) or non-amnestic (naMCI) subtype (11). Furthermore, it remains to be determined as to whether these two subtypes of MCI have different trajectories in relation to dementia (12-14).

It is well established that sleep plays a role in brain maturation and the development and maintenance of cognitive functions such as memory consolidation and learning (15). Although, the significance and functions of the various sleep stages are still not fully understood, there is, however, evidence showing that newly learned material and skills are consolidated during REM sleep (16). A link between brain cholinergic activity, timing, and density of REM sleep and cognitive functioning has also been demonstrated (17). Thus, deficiencies of REM sleep might correlate with or predict cognitive deficits in the elderly.

The formation of long-term memories requires a process of consolidation, which is facilitated by sleep. The formation of declarative (consciously recalled) memories, which are hippocampus-dependent, appears to benefit mainly from SWS (18). Recently, the focus has also been placed on stage 2 sleep and more precisely on sleep spindles, where research shows that overnight verbal memory retention is highly correlated with an increase in the number of sleep spindles (19). A hippocampal-neocortical framework of memory consolidation has been proposed whereby NREM SWS promotes the transformation of episodic memories from a state that depends on the hippocampus to one that is increasingly hippocampus-independent (20-22). Sleep deprivation after learning, however, would impair this process so that there is a greater retrieval of memories from the hippocampus (23).

\section{Sleep Quantity and Cognition}

Sleep loss may be acute, consisting of one continuous extended wake episode, or chronic, consisting of insufficient sleep over multiple days. A substantial amount of research has been conducted to understand the former but more recently the effect of chronic sleep loss has also been investigated (24-26). In one study, self-reported short sleep, tiredness, and fatigue were more strongly associated with subjective measures of cognitive function than with objective measures (24). Findings from the Whitehall II study show that adverse changes in sleep over time (decrease from 6,7 , or $8 \mathrm{~h}$, or increase from 7 or $8 \mathrm{~h}$ ) are associated with lower scores on a variety of cognitive function tests, but not memory function (27). Subtle changes in circadian phase, for example, those that commonly occur in the general population after returning to work after later weekend sleep may also affect cognitive function. One study demonstrated that memory and 
verbal fluency tasks are significantly reduced on Monday morning following delayed weekend sleep (28).

\section{Sleep Quality and Cognition}

Sleep quality is a measure of how well we actually sleep during the night. It is usually assessed via self-reported frequency of nocturnal awakenings; difficulty initiating sleep; waking up early; or waking up feeling tired, using validated tools such as the PSQI (29). Sleep quality may also play an important role in cognition. One study, in elderly women, however, found that while disturbed sleep was associated with an increased risk of developing a cognitive impairment, it was not associated with accelerated cognitive decline (30).

The Maastricht Ageing Study (MAAS) found that in middle aged and older adults subjective sleep complaints (i.e., difficulty falling asleep, waking up too early, and restless or disturbed sleep) were negatively associated with cognitive performance at the 3-year follow-up: The strongest effect being seen with early waking. The effects disappeared, however, after adjustment for depression, raising the question of whether poor quality of sleep leads directly to poor cognitive function, or whether poor sleep causes an increase in depressive symptoms, which then results in cognitive decline (31).

\section{Sleep and Cognitive Decline with Age}

Cognitive aging appears to be a very heterogeneous process. It is associated with a decline in working memory and new episodic memory performance with relative sparing of semantic memory, recognition memory, and priming [see review in Ref. (5)]. While many neuronal changes that are associated with cognitive decline appear to begin during middle age (32), the rate of decline for individuals appears to vary considerably (33). Furthermore, while studies have demonstrated that poor sleep (quantity, quality, and efficiency) are associated with cognitive decline (34). In a recent study, looking at 3,968 male and 4,821 female white participants, aged 50 years and over, from the English Longitudinal Study of Ageing (ELSA), we demonstrated that the relationship between sleep (quantity and quality) and cognition may vary with age. Whereas in the younger age group (50-64 years), both short ( $<6 \mathrm{~h}$ per night) and long ( $>8 \mathrm{~h}$ per night) sleep were associated with lower amnestic and non-amnestic scores, in the older age group (65+ years), associations were only significant for long sleep. Furthermore, while sleep quality was associated with both amnestic and non-amnestic scores in the older age group, it was not in the younger age group. These effects were regardless of duration of sleep (35). These observations need to be fully investigated in longitudinal studies.

\section{MECHANISMS UNDERLYING NEUROCOGNITIVE DISORDERS: THE ROLE OF SLEEP}

\section{Amyloid- $\beta$}

Alzheimer's disease is associated with the accumulation of amyloid- $\beta(A \beta)$ in extracellular plaques in the brain. This may result from either increased production or decrease in $A \beta$ clearance. This accumulation is thought to begin many years before the symptoms of $\mathrm{AD}$ are evident. It is now known that the concentrations of $A \beta$ show diurnal variation with the levels rising during wakefulness and falling during sleep $(36,37)$. It has been suggested that sleep facilitates the removal of $\mathrm{A} \beta$. A recent study in mice showed that during sleep, there was a $60 \%$ increase in interstitial space and a concomitant increase in the exchange of cerebrospinal fluid with interstitial fluid. This in turn increased the rate of $A \beta$ clearance; thus facilitating the removal of these harmful waste proteins that had built up between brain cells during waking hours (38). It has been postulated that sleep disturbances may inhibit this process and may be important in the pathogenesis of AD. Indeed, evidence suggests that individuals who are cognitively normal but who have biomarker evidence of amyloid plaque formation have worse quality sleep than individuals without evidence of plague formation. The study, which used actigraphy to measure sleep, demonstrated that both sleep efficiency and wake up time after sleep onset were effected (39).

\section{Tau-Phosphorylation}

Alzheimer's disease is associated with the accumulation of neurofibrillary tangles (NFT) in the brain. These are composed of a highly phosphorylated form of the microtubule-associated protein tau, which unlike the non-phosphorylated form, is unable to bind to microtubules (40). Several kinases are implicated in hyper-phosphorylation of tau including c-Jun $\mathrm{N}$-terminal kinase (JNK), which is also implicated in the deposition of amyloid plaque in $\mathrm{AD}$ brain (41).

Phosphorylation of tau via the extracellular signal-regulated kinase (ERK) pathway may occur under conditions where oxygen is lacking (hypoxia), which is a common feature of one of the most common sleep disorders known as Obstructive Sleep Apnoe (OSA). This in turn triggers neuronal degeneration and axonal dysfunction in both the cortex and brainstem (42) and may trigger cerebral amyloidogenesis (43).

\section{Inflammation}

Inflammatory processes play a key role in the association between sleep disturbances and cardiovascular disease (44). Likewise, it is possible that inflammatory mechanisms may play a crucial role in the relationship between sleep and cognition (35) and in the sleep-associated development of neurocognitive disorders (45). Studies indicate that neuro-inflammation is characterized by the activation of microglia, which are the principal immune cells of the central nervous system (CNS) and astrocytes, which are part of the blood-brain barrier. Their function is primarily to protect the CNS, but activation of these cells leads to the release of proinflammatory cytokines and chemokines, which may mediate cellular damage as well (46).

In a recent study, transcriptome analysis demonstrated that in 26 individuals, 1 week of insufficient versus sufficient sleep led to a change in the gene expression of 711 genes, which were up- or down-regulated (47). Many of these genes were involved in circadian biology and sleep homeostasis as well as oxidative stress, metabolism, inflammatory, immune, and stress responses. These changes in gene expression may be involved with the negative effects of sleep loss on health. 


\section{Melatonin Levels}

Melatonin, which is produced by the pineal gland at night, plays a major role in regulation of the biological clock and the sleepwake cycle. Studies indicate that melatonin levels are decreased in $\mathrm{AD}$ (48) and, reduced melatonin levels correlate with the severity of mental and sleep impairments in patient with dementia (49). Fast-release melatonin supplements given at bedtime may, however, improve cognitive and emotional performance and sleep/ wake cycle maintenance in patients with $\operatorname{MCI}(50,51)$.

\section{Genotype}

\section{Apolipoprotein-E Genotype}

Apolipoprotein-E (APOE) genotype is the strongest genetic risk factor for $\mathrm{AD}$ almost half of all $\mathrm{AD}$ patients have at least one $€ 4$ allele (52). The gene is important in lipid metabolism and cholesterol transport and polymorphic variation is associated with cardiovascular disease (53). The $€ 4$ allele is also pro-inflammatory and is associated with an increase in C-Reactive Protein (CRP) in population studies (54). Individuals with this genotype accumulate more $\mathrm{A} \beta$ are at high risk of developing AD. Studies indicate that that effect of the adverse APOE genotype may be amplified by sleep disruption (55-59). Moreover, better sleep consolidation has been shown to attenuate the effect of $A P O E$ genotype on incident $\mathrm{AD}(60)$.

\section{Circadian Clock Genes}

A single night of wakefulness can alter the epigenetic and transcriptional profile of core circadian clock genes in key metabolic tissues. A recent study looked at the association between circadian locomotor output cycle kaput (CLOCK) gene rs 4580704 $\mathrm{C} / \mathrm{G}$ with susceptibility of AD. It was found that among APOEe4 non-carriers, $\mathrm{C}$ carriers in CLOCK gene were associated with a high susceptibility of $\mathrm{AD}$; however, among APOE 4 carriers the functional polymorphism of clock gene rs $4580704 \mathrm{C} / \mathrm{G}$ was not associated with $\mathrm{AD}$ susceptibility (61). It remains to be seen if the expression of other circadian genes is altered in dementia patients.

\section{ROLE OF SLEEP AND SLEEP DISTURBANCES IN THE DEVELOPMENT AND MANAGEMENT OF NEUROCOGNITIVE DISORDERS}

Findings from prospective studies of sleep and cognitive outcomes along with results from observational and experimental studies suggest that poor sleep is a risk factor for cognitive decline and the development of AD [see review in Ref. (62)]. Furthermore, a study in JapaneseAmerican men without dementia showed that those individuals who report Excessive Daytime Sleepiness (EDS) at baseline are twice as likely to be diagnosed with incident dementia at 3-year follow-up compared to those without EDS (63). A similar finding was also reported in elderly French men and women (64).

Sleep problems are a common occurrence in those with MCI (65) and dementia (66). The importance of sleep problems in the development, progression, management, and treatment of these disorders is still not fully recognized. The sleep issues may be underreported by the sufferer or carer at early stages but may lead to behavioral problems that are predictive of future placement of an individual in a care home (67). Nevertheless, there is growing evidence to support that sleep might be useful as a surrogate marker for Preclinical AD (68) and, there is a need to improve sleep in at risk individuals.

Individuals with dementia experience highly fragmented sleep, with periods of night-time wakefulness and frequent daytime napping (66). In general, in individuals with dementia, the proportion of sleep at night that is spent in the lighter stages of sleep is increased and there is marked decrease in time spent in the more restorative SWS. In the latter stages of dementia, emotional and behavioral changes may become more problematic and these may be associated with a decrease in observed REM sleep $(69,70)$. Overall, sleep in people with dementia is lighter and shorter, as well as shifted to occur earlier in the day compared to a premorbid state.

Sleep impairments and changes in sleep architecture are characteristic features of $\mathrm{AD}$ (71). Increased stage 1 sleep and reduced SWS, as well as decreased sleep spindles, have been reported $(72,73)$.

\section{ROLE OF SLEEP DISORDERS IN DEVELOPMENT OF NEUROCOGNITIVE DISORDERS}

Sleep-disordered breathing (SDB) is very common in the elderly, with reported prevalence of between 24 and 42\% (74). It refers to conditions, which are characterized by intermittent reduction (hypopnea) or cessation (apnea) of breathing due to narrowing of the upper airways, which in turn leads to hypoxia. Cessation of breathing during sleep causes sleep fragmentation and arousal for sleep and subsequent EDS. It is associated with an increase in neurocognitive impairments $(56,75-77)$.

\section{Sleep Apnea}

The most common form of sleep apnea is OSA or obstructive sleep apnea syndrome (OSAS). OSA is characterized by recurrent sleep fragmentation and EDS, chronic intermittent hypoxia (CIH), hypercapnia, hypoventilation, peripheral and central inflammation, and changes in cerebral perfusion and glucose metabolism. Research suggests that the specific brain damage associated with OSAS could increase the risk of developing dementia (78). SDB may exacerbate cognitive dysfunction in AD (79). Indeed, positive correlations between the number of apneas occurring per hour (apnoe index) and severity of dementia in AD have been reported (80). It has been estimated that the prevalence of OSA in patients with dementing illnesses may be as high as $60 \%$ (81). But, it remains unclear, however, as to whether SDB precedes cognitive impairment or vice versa.

\section{Insomnia and Hypersomnia}

In the population of Western Europe, the estimated prevalence of insomnia is between 10 and 35\% (82). Furthermore, there is increasing evidence to suggest that insomniacs are at increased 
risk of cognitive decline [see review in Ref. (83)]. The detrimental performance may not be due to increased sleepiness; however, as insomniacs display a state of generalized hyperarousal with increased multiple sleep latency test (MSLT) scores (84).

Hypersomnia, which refers to either EDS or an excessive time spent sleeping, is a common feature of OSA and effected individuals have great trouble staying awake during the day. It is associated with neurocognitive impairments in both adults (85) and children (86).

\section{Circadian Rhythm Sleep Disorders}

The term "circadian rhythm sleep disorder" describes a chronic condition in which an individual's circadian rhythm of sleep and wakefulness is persistently or periodically out of phase with the expected environmental pattern. It is believed to occur when the biological pacemakers are decoupled from external cues as may occur for example in blind individuals. Several circadian sleep disorders have been classified including delayed sleep phase syndrome (DSPS), advanced sleep phase syndrome (ASPS), irregular sleep-wake patterns, and non-24-h sleep-wake syndrome in blind and sighted persons (87). Shift work and jet lag can also cause temporary misalignment of the circadian sleep-wake rhythm with environmental patterns.

\section{Circadian Rhythm Disorders}

Sleep-wake disturbances are a highly prevalent and often disabling feature of AD. There are changes in several biological systems including core body temperature control, melatonin secretion, and circadian variability. It has also been suggested that sleep-wake disturbances might be due to accumulation of $A \beta$. It is possible that this may be a reciprocal relationship as chronic sleep deprivation increases amyloid plaque deposition, and sleep extension results in fewer plaques in experimental models (88). Furthermore, $A \beta$ follows a diurnal pattern in that concentrations rise during wakefulness and fall during sleep $(36,37)$. Insomnia and circadian rhythm disorders are common causes for both caregiver burden and early institutionalization in patients for dementia $(89,90)$.

\section{REM Sleep Behavioral Disorder}

Rapid eye movement sleep behavior disorder (RBD) is a sleep disturbance that commonly occurs in Dementia with Lewy bodies (DLB) (91). It is a condition in which the normal paralysis that is associated with REM sleep does not occur; sufferers are able to act out their dreams or may sleepwalk become during sleep. It usually precedes cognitive impairment by years if not decades (92).

\section{PRESENCE OF SLEEP DISORDERS COULD DIRECT THE PROCESS OF DIAGNOSIS OF NEUROCOGNITIVE DISORDERS}

Poor sleep quality can be an early sign of amnestic cognitive decline (93). Furthermore, EDS may not only be an early marker but may also potentially be a reversible risk factor for cognitive decline and onset of dementia (64).

\section{Neuroimaging, Sleep and Neurocognitive Disorders}

Amyloid plaque formation causes neuronal damage far before cognitive impairment becomes manifest (94), which makes interventions targeting these pathological changes more challenging. There is therefore a need to develop early screening techniques. Amyloid may be imaged using the PET Pittsburgh compound (PiB-Pet). A recent cross-sectional study has shown that increased brain $A \beta$ is accompanied by lower peripheral levels of $\mathrm{A} \beta$. Moreover there was a relationship between $\mathrm{PiB}$ binding and plasma $A \beta$ (95). It may therefore be possible to use plasma $\mathrm{A} \beta$ combined with $\mathrm{PiB}$ binding as a risk biomarker. Although, it would be impractical to offer such screening to all individuals at risk of neurodegenerative disorders and other simpler risk markers are still needed.

Self-reported short and poor quality sleep in communitydwelling older adults is associated with greater $\mathrm{A} \beta$ burden (58). Likewise, in a recent study, it was shown that among older adults with MCI an increase in sleep SDB, as measured by polysomnography, was associated with greater $\mathrm{A} \beta$ deposition as measured by PiB-PET (59).

It is possible that sleep may normally play a vital role in removing potentially neurotoxic substances that accumulate in the awake state (38) and that sleep problems and sleep disorders may be an early marker of future neurocognitive disease development and treatment of sleep and sleep disorders might be modifier of risk in those who have a high amyloid load.

\section{PRESENCE OF SLEEP DISORDERS COULD DIRECT MANAGEMENT AND TREATMENT OF NEUROCOGNITIVE DISORDERS}

Research has shown that treatment of OSA via CPAP improves some aspects of cognitive function in dementia patients as well as in non-demented elderly patients with $\operatorname{OSA}(79,96)$. It remains to be determined if such treatments might prevent or slow future cognitive decline, leading to dementia.

\section{Pharmacological Sleep Intervention in Dementia}

Short-term sleep disturbances are treated using amongst others, antidepressants, benzodiazepines, and antihistamines. Benzodiazepines may decrease sleep the time taken to get to sleep "sleep latency" but drug therapies are not without side effects and long-term use may lead to increased daytime sleepiness and rebound insomnia (97).

A recent study demonstrated that MCI patients, who received fast-release melatonin at bedtime for between 15 and 60 months, exhibited significantly better performance on cognitive function tests compared to those with MCI who did not receive melatonin. Furthermore, it was reported that the group that received melatonin therapy required far less benzodiazepines to treat their associated sleep disturbances (51). 


\section{Non-Pharmacological Sleep Interventions in Dementia}

Many studies have previously focused on exercise, light or Cognitive Behavioral Therapy (CBT) for the treatment of sleep problems $(45,97)$. Exercise is important for physical and mental health and one study indicated that exercise may promote more restful sleep in adults (98). Bright light may be used to treat circadian rhythm disorders but there is a need to investigate this treatment further so as to develop gold standards for timing, mode of delivery, wavelength of light etc.

It remains to be seen if other interventions including CBT, to address any unhelpful beliefs and anxieties, might also be effective. Interventions may also include educating both carer and suffer with regards to how to improve and maintain good sleeping patterns. For example, by adapting the sleeping environment so that is quiet and dark, ensuring that there is a good pre-sleep wind down and ensuring that the sufferer does not spend time in the bedroom when they are not supposed to be. Social interactions might also be beneficial to sleep (97). On-going treatment for other conditions also needs to be considered as some blood pressure medication may affect sleep (99).

Further studies are required to determine if the treatment of sleep disturbances and sleep disorders may delay or prevent the development of AD and dementia. However, given the increasing population evidence to suggest that good sleep is required for general mental health and wellbeing it is important that the sufferers' sleep does not disrupt the carers' sleep, increasing their health burden.

\section{Clinical Trials of Sleep Interventions in Dementia Improving Sleep Quality}

A recent randomized clinical control trial demonstrated that lowintensity physical and mental activities could lead to an increase in self-reported sleep quality in older adults with self-reported cognitive and sleep difficulties (100). Further long-term studies are required with objective sleep measures to validate such studies and to see if they prevent cognitive decline.

\section{Use of Prolonged-Releases Melatonin Therapy}

In individuals with mild to moderate $\mathrm{AD}(n=80)$ prolongedrelease melatonin (PRM), given with standard therapy, led to a significantly better cognitive performance than those treated with placebo (101). These results contribute to the evidence that suggests that there may be a causal link between sleep and cognitive decline.

To date, it is not clear whether improvement to sleep of individuals with established sleep disturbances would delay progression of the disease. Likewise, whether treatment of early signs of sleep disturbances would lead to better outcomes and reduce the need to place the sufferer in a home. Further studies are required to determine if early interventions might (i) delay cognitive decline, (ii) improve carer stress and future health outcomes, and (iii) allow the individuals to be managed at home for longer rather than in care.

\section{PUBLIC HEALTH IMPORTANCE AND POLICY IMPLICATIONS}

Sleep is an integral part of life. Its importance for good physical and mental health is becoming increasing apparent (6) and this may be of particular relevance for older adults. The role of sleep-related cognitive failure in major incidents and disasters has received much attention, as their consequences are often catastrophic $(102,103)$. As the rate of dementia is expected to increase dramatically across the world, it is important to fully understand the role that sleep and sleep disorders play in the prevention, development, and management of this disorder. It is important to increase the public awareness of the importance of sleep and to facilitate the early detection of sleep problems and disorders.

Given the emerging important relationship between sleep and cognition and cognitive impairment, assessment of sleep should be part of clinical assessment of patients presenting with cognitive impairment. To this end, the sleep study group of the Italian dementia research association (SINDem) has recently put forward recommendations for the clinical assessment and management of sleep disorders in individuals with MCI and Dementia (104). Indeed, intellectual decline associated with OSA may be misinterpreted as early dementia but may improve with appropriate OSA treatment (105). Knowledge of any underlying sleep disorders may also potentially affect the dementia diagnosis and subsequent management. Sleep apnea syndrome constitutes more than $8 \%$ of patients presenting with cognitive impairment in young adults, and it is imperative that this potentially reversible form of cognitive impairment is identified and treated early (106). This is particularly important as OSA has been identified as a risk factor for development of future dementia (107) and when treated with CPAP slower progression of the dementia was observed (108).

Studies are required to see if improvements in sleep can delay cognitive decline in at risk individuals. And research is needed to further explore the therapeutic effects but also potentially adverse effects of sleep interventions in individuals with known sleep disorders. Identifying, which individuals might be at high risk of dementia or, who may have underlying sleep problems, would allow the identification of individuals who might benefit from targeted sleep intervention. However, it is also important to appreciate that patients with dementia are at higher risk of being prescribed sleeping tablets (109-111) and, for those dementia patients with undiagnosed OSA the use of hypnotics may exacerbate cognitive impairment due to drug side effects and worsening of the sleep disorder (112).

It is necessary to explore the mechanisms underlying dementia and to determine if there may be different treatment regimens appropriate for different causative pathways. Early diagnosis of sleep disorders and sleep problems associated with dementia is required and referral routes need to be clearly agreed. There is a need for a good evidence base with regards to the effectiveness of proposed interventions in patients with dementia, which needs to be derived from large evidence-based clinical trials with objective measurements of sleep. 


\section{CONCLUSION}

A vast amount of research has been conducted into the effect of sleep and sleep disorders on cognition. Age-dependent changes in sleep have been well documented. Studies suggest that a "sufficient" quantity and quality of sleep are required for many aspects of both memory and non-memory cognitive function (30). The amount of sleep that constitutes "sufficient" sleep, however, continues to be debated. Nevertheless, it is generally agreed that people at the extremes of the sleep distribution, i.e., short $(<5 \mathrm{~h})$ and long $(>9 \mathrm{~h})$ sleepers are subject to cognitive deficits and accelerated cognitive aging. Proper alignment between sleepwakefulness and internal circadian time is also crucial for optimal cognitive performance. It is accepted that many individuals with

\section{REFERENCES}

1. Prince M, Bryce R, Albanese E, Wimo A, Ribeiro W, Ferri CP. The global prevalence of dementia: a systematic review and metaanalysis. Alzheimers Dement (2013) 9(1):63-75. doi:10.1016/j.jalz.2012.11.007

2. Wimo A, Jonsson L, Bond J, Prince M, Winblad B. The worldwide economic impact of dementia 2010. Alzheimers Dement (2013) 9(1):1-11. doi:10.1016/j. jalz.2012.11.006

3. Cappuccio FP, D'Elia L, Strazzullo P, Miller MA. Sleep duration and all-cause mortality: a systematic review and meta-analysis of prospective studies. Sleep (2010) 33(5):585-92.

4. Bliwise DL. Normal Aging. Forth ed. Philadelphia, PA: WB Saunders Company (2005). p. 24-38.

5. Pace-Schott EF, Spencer RM. Age-related changes in the cognitive function of sleep. Prog Brain Res (2011) 191:75-89. doi:10.1016/ B978-0-444-53752-2.00012-6

6. Miller MA, Wright H, Hough J, Cappuccio FP. Sleep and cognition. In: Idzikowski C, editor. Sleep and its Disorders Affect Society. InTech (2014). p. 3-28. doi:10.5772/58735

7. Van Cauter E, Leproult R, Plat L. Age-related changes in slow wave sleep and REM sleep and relationship with growth hormone and cortisol levels in healthy men. JAMA (2000) 284(7):861-8. doi:10.1001/jama.284.7.861

8. Sowell ER, Peterson BS, Thompson PM, Welcome SE, Henkenius AL, Toga AW. Mapping cortical change across the human life span. Nat Neurosci (2003) 6(3):309-15. doi:10.1038/nn1008

9. Mander BA, Rao V, Lu B, Saletin JM, Lindquist JR, Ancoli-Israel S, et al. Prefrontal atrophy, disrupted NREM slow waves and impaired hippocampal-dependent memory in aging. Nat Neurosci (2013) 16(3):357-64. doi:10.1038/nn.3324

10. Luca G, Haba Rubio J, Andries D, Tobback N, Vollenweider P, Waeber G, et al. Age and gender variations of sleep in subjects without sleep disorders. Ann Med (2015) 47:482-91. doi:10.3109/07853890.2015.1074271

11. Petersen RC. Mild cognitive impairment as a diagnostic entity. J Intern Med (2004) 256:183-94. doi:10.1111/j.1365-2796.2004.01388.x

12. Sachdev PS, Lipnicki DM, Crawford J, Reppermund S, Kochan NA, Trollor JN, et al. Risk profiles of subtypes of mild cognitive impairment: the sydney memory and ageing study. J Am Geriatr Soc (2012) 60:24-33. doi:10.1111/j.1532-5415.2011.03774.x

13. Palmer K, Backman L, Winblad B, Fratiglioni L. Mild cognitive impairment in the general population: occurrence and progression to Alzheimer disease. Am J Geriatr Psychiatry (2008) 16:603-11. doi:10.1097/ JGP.0b013e3181753a64

14. Fischer P, Jungwirth S, Zehetmayer S, Weissgram S, Hoenigschnabl S, Gelpi E, et al. Conversion from subtypes of mild cognitive impairment to Alzheimer dementia. Neurology (2007) 68:288-91. doi:10.1212/01. wnl.0000252358.03285.9d

15. Spruyt K, Gozal D. Sleep in children: the evolving challenge of catching enough and quality Zzz's. First ed. In: Cappuccio FP, Miller MA, Lockley SW, editors. Sleep, Health, and Society from Aetiology to Public Health. Oxford: Oxford University Press (2010). p. 215-38. dementia have sleeping problems but despite this sleep problems in dementia and, the possibility that poor sleep may contribute to the development and progression of dementia is largely ignored. New clinical guidelines are required. Sleep disturbances and sleep disorders need to be carefully investigated using sleep history, physical examination, questionnaires etc., in both individuals with and in those at risk of development of dementia.

Further research is required to understand the associations and mechanisms involved in more detail, where the findings could have huge impacts in many areas of medicine, from normal aging to neurocognitive disorders and public health. Evidencebased research is required to develop a framework for diagnosis and treatment of sleep disorders, especially in patients with dementia.

16. Karni A, Tanne D, Rubenstein BS, Askenasy JJ, Sagi D. Dependence on REM sleep of overnight improvement of a perceptual skill. Science (1994) 265(5172):679-82. doi:10.1126/science.8036518

17. Spiegel R, Herzog A, Koberle S. Polygraphic sleep criteria as predictors of successful aging: an exploratory longitudinal study. Biol Psychiatry (1999) 45(4):435-42. doi:10.1016/S0006-3223(98)00042-0

18. Born J, Rasch B, Gais S. Sleep to remember. Neuroscientist (2006) 12(5):410 24. doi:10.1177/1073858406292647

19. Clemens Z, Fabo D, Halasz P. Overnight verbal memory retention correlates with the number of sleep spindles. Neuroscience (2005) 132(2):529-35. doi:10.1016/j.neuroscience.2005.01.011

20. Diekelmann S, Born J. The memory function of sleep. Nat Rev Neurosci (2010) 11:114-26. doi:10.1038/nrn2762

21. Walker MP. The role of sleep in cognition and emotion. Ann N Y Acad Sci (2009) 1156:168-97. doi:10.1111/j.1749-6632.2009.04416.x

22. Nadel L, Moscovitch M. Memory consolidation, retrograde amnesia and the hippocampal complex. Curr Opin Neurobiol (1997) 7:217-27. doi:10.1016/ S0959-4388(97)80010-4

23. Gais S, Albouy G, Boly M, Dang-Vu TT, Darsaud A, Desseilles M, et al. Sleep transforms the cerebral trace of declarative memories. Proc Natl Acad Sci US A (2007) 104:18778-83. doi:10.1073/pnas.0705454104

24. Kronholm E, Sallinen M, Suutama T, Sulkava R, Era P, Partonen T. Selfreported sleep duration and cognitive functioning in the general population. J Sleep Res (2009) 18(4):436-46. doi:10.1111/j.1365-2869.2009.00765.x

25. Nebes RD, Buysse DJ, Halligan EM, Houck PR, Monk TH. Self-reported sleep quality predicts poor cognitive performance in healthy older adults. J Gerontol B Psychol Sci Soc Sci (2009) 64(2):180-7. doi:10.1093/geronb/ gbn037

26. Xu L, Jiang CQ, Lam TH, Liu B, Jin YL, Zhu T, et al. Short or long sleep duration is associated with memory impairment in older Chinese: the Guangzhou Biobank cohort study. Sleep (2011) 34(5):575-80.

27. Ferrie JE, Shipley MJ, Akbaraly TN, Marmot MG, Kivimaki M, SinghManoux A. Change in sleep duration and cognitive function: findings from the Whitehall II study. Sleep (2011) 34(5):565-73.

28. Yang C-M, Spielman AJ. The effect of a delayed weekend sleep pattern on sleep and monitoring functioning. Psychol Health (2001) 16(6):715-25. doi:10.1080/08870440108405869

29. Buysse DJ, Reynolds CF III, Monk TH, Berman SR, Kupfer DJ. The Pittsburgh sleep quality index: a new instrument for psychiatric practice and research. Psychiatry Res (1989) 28(2):193-213. doi:10.1016/0165-1781(89)90047-4

30. Tworoger SS, Lee S, Schernhammer ES, Grodstein F. The association of self-reported sleep duration, difficulty sleeping, and snoring with cognitive function in older women. Alzheimer Dis Assoc Disord (2006) 20(1):41-8 doi:10.1097/01.wad.0000201850.52707.80

31. Jelicic M, Bosma H, Ponds RW, van Boxtel MP, Houx PJ, Jolles J. Subjective sleep problems in later life as predictors of cognitive decline. Report from the maastricht ageing study (MAAS). Int J Geriatr Psychiatry (2002) 17(1):73-7. doi:10.1002/gps.529

32. Salthouse TA. When does age-related cognitive decline begin? Neurobiol Aging (2009) 30(4):507-14. doi:10.1016/j.neurobiolaging.2008.09.023 
33. Ardila A. Normal aging increases cognitive heterogeneity: analysis of dispersion in WAIS-III scores across age. Arch Clin Neuropsychol (2007) 22(8):1003-11. doi:10.1016/j.acn.2007.08.004

34. Elcombe EL, Lagopoulos J, Duffy SL, Lewis SJ, Norrie L, Hickie IB, et al. Hippocampal volume in older adults at risk of cognitive decline: the role of sleep, vascular risk, and depression. J Alzheimers Dis (2015) 44(4):1279-90. doi:10.3233/JAD-142016

35. Miller MA, Wright H, Ji C, Cappuccio FP. Cross-sectional study of sleep quantity and quality and amnestic and non-amnestic cognitive function in an ageing population: the english longitudinal study of ageing (ELSA). PLoS One (2014) 9(6):e100991. doi:10.1371/journal.pone.0100991

36. Huang Y, Potter R, Sigurdson W, Santacruz A, Shih S, Ju YE, et al. Effects of age and amyloid deposition on Abeta dynamics in the human central nervous system. Arch Neurol (2012) 69(1):51-8. doi:10.1001/archneurol.2011.235

37. Lucey BP, Bateman RJ. Amyloid-beta diurnal pattern: possible role of sleep in Alzheimer's disease pathogenesis. Neurobiol Aging (2014) 35(Suppl 2):S29-34. doi:10.1016/j.neurobiolaging.2014.03.035

38. Xie L, Kang H, Xu Q, Chen MJ, Liao Y, Thiyagarajan M, et al. Sleep drives metabolite clearance from the adult brain. Science (2013) 342(6156):373-7. doi:10.1126/science.1241224

39. Ju YE, McLeland JS, Toedebusch CD, Xiong C, Fagan AM, Duntley SP, et al. Sleep quality and preclinical Alzheimer disease. JAMA Neurol (2013) 70(5):587-93. doi:10.1001/jamaneurol.2013.2334

40. Mattson MP. Effects of microtubule stabilization and destabilization on tau immunoreactivity in cultured hippocampal neurons. Brain Res (1992) 582(1):107-18. doi:10.1016/0006-8993(92)90323-2

41. Ploia C, Antoniou X, Sclip A, Grande V, Cardinetti D, Colombo A, et al. JNK plays a key role in tau hyperphosphorylation in Alzheimer's disease models. J Alzheimers Dis (2011) 26(2):315-29. doi:10.3233/ JAD-2011-110320

42. Fang H, Zhang LF, Meng FT, Du X, Zhou JN. Acute hypoxia promote the phosphorylation of tau via ERK pathway. Neurosci Lett (2010) 474(3):173-7. doi:10.1016/j.neulet.2010.03.037

43. Daulatzai MA. Death by a thousand cuts in Alzheimer's disease: hypoxia - the prodrome. NeurotoxRes(2013) 24(2):216-43. doi:10.1007/s12640-013-9379-2

44. Miller MA, Cappuccio FP. Inflammation, sleep, obesity and cardiovascular disease. Curr Vasc Pharmacol (2007) 5(2):93-102. doi:10.2174/157016107780368280

45. Landry GJ, Liu-Ambrose T. Buying time: a rationale for examining the use of circadian rhythm and sleep interventions to delay progression of mild cognitive impairment to Alzheimer's disease. Front Aging Neurosci (2014) 6:325. doi:10.3389/fnagi.2014.00325

46. Minagar A, Shapshak P, Fujimura R, Ownby R, Heyes M, Eisdorfer C. The role of macrophage/microglia and astrocytes in the pathogenesis of three neurologic disorders: HIV-associated dementia, Alzheimer disease, and multiple sclerosis. J Neurol Sci (2002) 202(1-2):13-23. doi:10.1016/ S0022-510X(02)00207-1

47. Moller-Levet CS, Archer SN, Bucca G, Laing EE, Slak A, Kabiljo R, et al. Effects of insufficient sleep on circadian rhythmicity and expression amplitude of the human blood transcriptome. Proc Natl Acad Sci U S A (2013) 110(12):E1132-41. doi:10.1073/pnas.1217154110

48. Tohgi H, Abe T, Takahashi S, Kimura M, Takahashi J, Kikuchi T. Concentrations of serotonin and its related substances in the cerebrospinal fluid in patients with Alzheimer type dementia. Neurosci Lett (1992) 141(1):9-12. doi:10.1016/0304-3940(92)90322-X

49. Mishima K, Tozawa T, Satoh K, Matsumoto Y, Hishikawa Y, Okawa M. Melatonin secretion rhythm disorders in patients with senile dementia of Alzheimer's type with disturbed sleep-waking. Biol Psychiatry (1999) 45(4):417-21. doi:10.1016/S0006-3223(97)00510-6

50. Furio AM, Brusco LI, Cardinali DP. Possible therapeutic value of melatonin in mild cognitive impairment: a retrospective study. J Pineal Res (2007) 43(4):404-9. doi:10.1111/j.1600-079X.2007.00491.x

51. Cardinali DP, Vigo DE, Olivar N, Vidal MF, Furio AM, Brusco LI. Therapeutic application of melatonin in mild cognitive impairment. Am J Neurodegener Dis (2012) 1(3):280-91.

52. Kim J, Basak JM, Holtzman DM. The role of apolipoprotein E in Alzheimer's disease. Neuron (2009) 63(3):287-303. doi:10.1016/j.neuron.2009.06.026

53. Schilling S, DeStefano AL, Sachdev PS, Choi SH, Mather KA, DeCarli CD, et al. APOE genotype and MRI markers of cerebrovascular disease: systematic review and meta-analysis. Neurology (2013) 81(3):292-300. doi:10.1212/ WNL.0b013e31829bfda4

54. Hubacek JA, Peasey A, Pikhart H, Stavek P, Kubinova R, Marmot M, et al. APOE polymorphism and its effect on plasma C-reactive protein levels in a large general population sample. Hum Immunol (2010) 71(3):304-8. doi:10.1016/j.humimm.2010.01.008

55. Cosentino FI, Bosco P, Drago V, Prestianni G, Lanuzza B, Iero I, et al. The APOE epsilon4 allele increases the risk of impaired spatial working memory in obstructive sleep apnea. Sleep Med (2008) 9(8):831-9. doi:10.1016/j. sleep.2007.10.015

56. Kaushal N, Ramesh V, Gozal D. Human apolipoprotein E4 targeted replacement in mice reveals increased susceptibility to sleep disruption and intermittent hypoxia. Am J Physiol Regul Integr Comp Physiol (2012) 303(1):R19-29. doi:10.1152/ajpregu.00025.2012

57. O’Hara R, Schroder CM, Kraemer HC, Kryla N, Cao C, Miller E, et al. Nocturnal sleep apnea/hypopnea is associated with lower memory performance in APOE epsilon4 carriers. Neurology (2005) 65(4):642-4. doi:10.1212/01.wnl.0000173055.75950.bf

58. Spira AP, Gamaldo AA, An Y, Wu MN, Simonsick EM, Bilgel M, et al. Self-reported sleep and beta-amyloid deposition in community-dwelling older adults. JAMA Neurol (2013) 70(12):1537-43. doi:10.1001/ jamaneurol.2013.4258

59. Spira AP, Yager C, Brandt J, Smith GS, Zhou Y, Mathur A, et al. Objectively measured sleep and beta-amyloid burden in older adults: a pilot study. SAGE Open Med (2014) 2:1-6. doi:10.1177/2050312114546520

60. Lim AS, Yu L, Kowgier M, Schneider JA, Buchman AS, Bennett DA. Modification of the relationship of the apolipoprotein E epsilon4 allele to the risk of Alzheimer disease and neurofibrillary tangle density by sleep. JAMA Neurol (2013) 70(12):1544-51. doi:10.1001/jamaneurol.2013.4215

61. Chen HF, Huang CQ, You C, Wang ZR, Si-qing H. Polymorphism of CLOCK gene rs $4580704 \mathrm{C}>\mathrm{G}$ is associated with susceptibility of Alzheimer's disease in a Chinese population. Arch Med Res (2013) 44(3):203-7. doi:10.1016/j. arcmed.2013.01.002

62. Spira AP, Chen-Edinboro LP, Wu MN, Yaffe K. Impact of sleep on the risk of cognitive decline and dementia. Curr Opin Psychiatry (2014) 27(6):478-83. doi:10.1097/YCO.0000000000000106

63. Foley D, Monjan A, Masaki K, Ross W, Havlik R, White L, et al. Daytime sleepiness is associated with 3-year incident dementia and cognitive decline in older Japanese-American men. J Am Geriatr Soc (2001) 49(12):1628-32. doi:10.1111/j.1532-5415.2001.49271.x

64. Jaussent I, Bouyer J, Ancelin ML, Berr C, Foubert-Samier A, Ritchie K, et al. Excessive sleepiness is predictive of cognitive decline in the elderly. Sleep (2012) 35(9):1201-7. doi:10.5665/sleep.2070

65. van der Linde R, Stephan BC, Matthews FE, Brayne C, Savva GM. Behavioural and psychological symptoms in the older population without dementia - relationship with socio-demographics, health and cognition. BMC Geriatr (2010) 10:87. doi:10.1186/1471-2318-10-87

66. Bliwise DL. Sleep in normal aging and dementia. Sleep (1993) 16(1):40-81.

67. Desai AK, Schwartz L, Grossberg GT. Behavioral disturbance in dementia. Curr Psychiatry Rep (2012) 14(4):298-309. doi:10.1007/s11920-012-0288-5

68. Hita-Yanez E, Atienza M, Cantero JL. Polysomnographic and subjective sleep markers of mild cognitive impairment. Sleep (2013) 36(9):1327-34. doi:10.5665/sleep. 2956

69. Desai AK, Grossberg GT. Recognition and management of behavioral disturbances in dementia. Prim Care Companion J Clin Psychiatry (2001) 3(3):93-109. doi:10.4088/PCC.v03n0301

70. Prinz PN, Vitiello MV, Raskind MA, Thorpy MJ. Geriatrics: sleep disorders and aging. N Engl J Med (1990) 323(8):520-6. doi:10.1056/ NEJM199008233230805

71. Petit D, Gagnon JF, Fantini ML, Ferini-Strambi L, Montplaisir J. Sleep and quantitative EEG in neurodegenerative disorders. J Psychosom Res (2004) 56(5):487-96. doi:10.1016/j.jpsychores.2004.02.001

72. Loewenstein RJ, Weingartner H, Gillin JC, Kaye W, Ebert M, Mendelson WB. Disturbances of sleep and cognitive functioning in patients with dementia. Neurobiol Aging (1982) 3(4):371-7. doi:10.1016/0197-4580(82)90025-2

73. Reynolds CF III, Kupfer DJ, Taska LS, Hoch CC, Spiker DG, Sewitch DE, et al. EEG sleep in elderly depressed, demented, and healthy subjects. Biol Psychiatry (1985) 20(4):431-42. doi:10.1016/0006-3223(85)90045-9 
74. Ancoli-Israel S, Ayalon L. Diagnosis and treatment of sleep disorders in older adults. Am J Geriatr Psychiatry (2006) 14(2):95-103. doi:10.1097/01. JGP.0000196627.12010.d1

75. Ancoli-Israel S, Klauber MR, Butters N, Parker L, Kripke DF. Dementia in institutionalized elderly: relation to sleep apnea. J Am Geriatr Soc (1991) 39(3):258-63. doi:10.1111/j.1532-5415.1991.tb01647.x

76. Ancoli-Israel S, Kripke DF, Klauber MR, Mason WJ, Fell R, Kaplan O. Sleep-disordered breathing in community-dwelling elderly. Sleep (1991) 14(6):486-95.

77. Yaffe K, Laffan AM, Harrison SL, Redline S, Spira AP, Ensrud KE, et al. Sleep-disordered breathing, hypoxia, and risk of mild cognitive impairment and dementia in older women. JAMA (2011) 306(6):613-9. doi:10.1001/ jama.2011.1115

78. Kim SJ, Lee JH, Lee DY, Jhoo JH, Woo JI. Neurocognitive dysfunction associated with sleep quality and sleep apnea in patients with mild cognitive impairment. Am J Geriatr Psychiatry (2011) 19(4):374-81. doi:10.1097/ JGP.0b013e3181e9b976

79. Ancoli-Israel S, Palmer BW, Cooke JR, Corey-Bloom J, Fiorentino L, Natarajan L, et al. Cognitive effects of treating obstructive sleep apnea in Alzheimer's disease: a randomized controlled study. J Am Geriatr Soc (2008) 56(11):2076-81. doi:10.1111/j.1532-5415.2008.01934.x

80. Hoch CC, Reynolds CF III, Kupfer DJ, Houck PR, Berman SR, Stack JA. Sleep-disordered breathing in normal and pathologic aging. J Clin Psychiatry (1986) 47(10):499-503.

81. Guarnieri B, Adorni F, Musicco M, Appollonio I, Bonanni E, Caffarra P, et al. Prevalence of sleep disturbances in mild cognitive impairment and dementing disorders: a multicenter Italian clinical cross-sectional study on 431 patients. Dement Geriatr Cogn Disord (2012) 33(1):50-8. doi:10.1159/000335363

82. Ohayon MM, Partinen M. Insomnia and global sleep dissatisfaction in Finland. J Sleep Res (2002) 11(4):339-46. doi:10.1046/j.1365-2869.2002.00317.x

83. Fortier-Brochu E, Beaulieu-Bonneau S, Ivers H, Morin CM. Insomnia and daytime cognitive performance: a meta-analysis. Sleep Med Rev (2012) 16(1):83-94. doi:10.1016/j.smrv.2011.03.008

84. Bonnet MH, Arand DL. 24-Hour metabolic rate in insomniacs and matched normal sleepers. Sleep (1995) 18(7):581-8.

85. Lal C, Strange C, Bachman D. Neurocognitive impairment in obstructive sleep apnea. Chest (2012) 141(6):1601-10. doi:10.1378/chest.11-2214

86. O'Brien LM. The neurocognitive effects of sleep disruption in children and adolescents. Child Adolesc Psychiatr Clin N Am (2009) 18(4):813-23. doi:10.1016/j.chc.2009.04.008

87. Zisapel N. Circadian rhythm sleep disorders: pathophysiology and potential approaches to management. CNS Drugs (2001) 15(4):311-28. doi:10.2165/00023210-200115040-00005

88. Lim MM, Gerstner JR, Holtzman DM. The sleep-wake cycle and Alzheimer's disease: what do we know? Neurodegener Dis Manag (2014) 4(5):351-62. doi:10.2217/nmt.14.33

89. Kim SS, Oh KM, Richards K. Sleep disturbance, nocturnal agitation behaviors, and medical comorbidity in older adults with dementia: relationship to reported caregiver burden. Res Gerontol Nurs (2014) 7(5):206-14. doi:10.3928/19404921-20140512-01

90. Lee DR, Thomas AJ. Sleep in dementia and caregiving - assessment and treatment implications: a review. Int Psychogeriatr (2011) 23(2):190-201. doi:10.1017/S1041610210001894

91. Ferman TJ, Boeve BF, Smith GE, Silber MH, Lucas JA, Graff-Radford NR, et al. Dementia with Lewy bodies may present as dementia and REM sleep behavior disorder without parkinsonism or hallucinations. J Int Neuropsychol Soc (2002) 8(7):907-14. doi:10.1017/S1355617702870047

92. Fulda S. Idiopathic REM sleep behavior disorder as a long-term predictor of neurodegenerative disorders. EPMA J (2011) 2(4):451-8. doi:10.1007/ s13167-011-0096-8

93. Potvin O, Lorrain D, Forget H, Dube M, Grenier S, Preville M, et al. Sleep quality and 1-year incident cognitive impairment in community-dwelling older adults. Sleep (2012) 35(4):491-9. doi:10.5665/sleep.1732

94. Murray IV, Proza JF, Sohrabji F, Lawler JM. Vascular and metabolic dysfunction in Alzheimer's disease: a review. Exp Biol Med (Maywood) (2011) 236(7):772-82. doi:10.1258/ebm.2011.010355

95. Devanand DP, Schupf N, Stern Y, Parsey R, Pelton GH, Mehta P, et al. Plasma Abeta and PET PiB binding are inversely related in mild cognitive impairment. Neurology (2011) 77(2):125-31. doi:10.1212/WNL.0b013e318224afb7
96. Weaver TE, Chasens ER. Continuous positive airway pressure treatment for sleep apnea in older adults. Sleep Med Rev (2007) 11(2):99-111. doi:10.1016/j. smrv.2006.08.001

97. Deschenes CL, McCurry SM. Current treatments for sleep disturbances in individuals with dementia. Curr Psychiatry Rep (2009) 11(1):20-6. doi:10.1007/s11920-009-0004-2

98. King AC, Oman RF, Brassington GS, Bliwise DL, Haskell WL. Moderateintensity exercise and self-rated quality of sleep in older adults. A randomized controlled trial. JAMA (1997) 277(1):32-7. doi:10.1001/jama.277.1.32

99. Monti JM. Disturbances of sleep and wakefulness associated with the use of antihypertensive agents. Life Sci (1987) 41(17):1979-88. doi:10.1016/0024-3205(87)90471-1

100. Pa J, Goodson W, Bloch A, King AC, Yaffe K, Barnes DE. Effect of exercise and cognitive activity on self-reported sleep quality in community-dwelling older adults with cognitive complaints: a randomized controlled trial. J Am Geriatr Soc (2014) 62(12):2319-26. doi:10.1111/jgs.13158

101. Wade AG, Farmer M, Harari G, Fund N, Laudon M, Nir T, et al. Add-on prolonged-release melatonin for cognitive function and sleep in mild to moderate Alzheimer's disease: a 6-month, randomized, placebo-controlled, multicenter trial. Clin Interv Aging (2014) 9:947-61. doi:10.2147/CIA.S65625

102. Dinges DF. An overview of sleepiness and accidents. J Sleep Res (1995) 4(S2):4-14. doi:10.1111/j.1365-2869.1995.tb00220.x

103. Mitler MM, Carskadon MA, Czeisler CA, Dement WC, Dinges DF, Graeber RC. Catastrophes, sleep, and public policy: consensus report. Sleep (1988) 11(1):100-9.

104. Guarnieri B, Musicco M, Caffarra P, Adorni F, Appollonio I, Arnaldi D, et al. Recommendations of the Sleep Study Group of the Italian Dementia Research Association (SINDem) on clinical assessment and management of sleep disorders in individuals with mild cognitive impairment and dementia: a clinical review. Neurol Sci (2014) 35(9):1329-48. doi:10.1007/ s10072-014-1873-7

105. Engleman HM, Kingshott RN, Martin SE, Douglas NJ. Cognitive function in the sleep apnea/hypopnea syndrome (SAHS). Sleep (2000) 23(Suppl 4):S102-8.

106. Panegyres PK, Frencham K. Course and causes of suspected dementia in young adults: a longitudinal study. Am J Alzheimers Dis Other Demen (2007) 22(1):48-56. doi:10.1177/1533317506295887

107. Chang WP, Liu ME, Chang WC, Yang AC, Ku YC, Pai JT, et al. Sleep apnea and the risk of dementia: a population-based 5-year follow-up study in Taiwan. PLoS One (2013) 8(10):e78655. doi:10.1371/journal. pone. 0078655

108. Troussiere AC, Charley CM, Salleron J, Richard F, Delbeuck X, Derambure $\mathrm{P}$, et al. Treatment of sleep apnoea syndrome decreases cognitive decline in patients with Alzheimer's disease. J Neurol Neurosurg Psychiatry (2014) 85(12):1405-8. doi:10.1136/jnnp-2013-307544

109. Futtrup TB, Helnaes AK, Schultz H, Jensen M, Reuther LO. Psychotropic medication in a randomly selected group of citizens receiving residential or home care. Dan Med J (2014) 61(12):A4965.

110. Okumura Y, Togo T, Fujita J. Trends in use of psychotropic medications among patients treated with cholinesterase inhibitors in Japan from 2002 to 2010. Int Psychogeriatr (2015) 27(3):407-15. doi:10.1017/S1041610214001975

111. Parsons C, Haydock J, Mathie E, Baron N, Machen I, Stevenson E, et al. Sedative load of medications prescribed for older people with dementia in care homes. BMC Geriatr (2011) 11:56. doi:10.1186/1471-2318-11-56

112. Li CT, Bai YM, Lee YC, Mao WC, Chen MH, Tu PC, et al. High dosage of hypnotics predicts subsequent sleep-related breathing disorders and is associated with worse outcomes for depression. Sleep (2014) 37(4):803B-9B. doi:10.5665/sleep.3594

Conflict of Interest Statement: The author declares that the research was conducted in the absence of any commercial or financial relationships that could be construed as a potential conflict of interest.

Copyright $\odot 2015$ Miller. This is an open-access article distributed under the terms of the Creative Commons Attribution License (CC BY). The use, distribution or reproduction in other forums is permitted, provided the original author(s) or licensor are credited and that the original publication in this journal is cited, in accordance with accepted academic practice. No use, distribution or reproduction is permitted which does not comply with these terms. 